\title{
Number of coils necessary to treat cerebral aneurysms according to each size group: a study based on a series of 952 embolized aneurysms
}

Quantidade de molas necessárias para o tratamento endovascular dos aneurismas cerebrais de acordo com seu tamanho: estudo baseado em uma série de 952 aneurismas embolizados José Ricardo Vanzin', Daniel Giansante Abud², Marco Tulio Salles Rezende ${ }^{3}$, Jacques Moret ${ }^{4}$

\begin{abstract}
Objective: The Brazilian public health system determines a quantity of coils allowed to treat a cerebral aneurysm. The goal of this paper was to determine the number of coils necessary to treat an aneurysm based on size. Methods: All patients harboring an aneurysm treated by endovascular approach between 1999 and 2003 were reviewed. Results: There were 952 aneurysms included. Mean diameter sac was $8.2 \mathrm{~mm}$ with 7.9 coils per aneurysm. Out of $462 \mathrm{small}$ aneurysms, mean size was $4.8 \mathrm{~mm}$, with 4.6 coils/aneurysm used. A total of $315 \mathrm{medium}$ aneurysms were treated, mean size was $8.6 \mathrm{~mm}$, with 8.2 coils. Out of 135 large, mean size was $17 \mathrm{~mm}$, with 16.1 coils. Forty giant aneurysms were treated with a mean size of $32 \mathrm{~mm}$ and 28.7 coils. Conclusions: We propose size as a reference to predict the number of coils necessary to treat each aneurysm: one coil for each millimeter of diameter.
\end{abstract}

Key words: intracranial aneurysm, endovascular treatment, coils.

\section{RESUMO}

Objetivo: O sistema público brasileiro determina uma quantidade limitada de molas permitida para o tratamento endovascular dos aneurismas cerebrais. 0 objetivo deste trabalho foi determinar a quantidade de molas necessária para tratar um aneurisma usando tamanho como referência. Método: Foram revisados todos os pacientes com aneurismas embolizados entre 1999 e 2003. Resultados: No total, 952 aneurismas foram analisados. 0 diâmetro médio foi de $8,2 \mathrm{~mm}$, com 7,9 molas usadas por aneurisma. Do total, 462 aneurismas eram pequenos, com tamanho médio de 4,8 mm e 4,6 molas/aneurisma. Foram tratados 315 aneurismas médios, com tamanho médio de 8,6 mm e 8,2 molas/aneurisma. Dentre os 135 aneurismas grandes, o tamanho foi de 17 mm, com 16,1 molas/aneurisma. Foram tratados 40 aneurismas gigantes, com média de 32 mm e 28,7 molas/aneurisma. Conclusão: Propomos que se utilize o tamanho do aneurisma como referência para prever o número de molas necessário para embolização: uma mola para cada milímetro de tamanho do saco aneurismático.

Palavras-Chave: aneurisma intracraniano, tratamento endovascular, molas.

The endovascular treatment ofintracranial aneurysms gained strength and credibility after the International Subarachnoid Aneurysm Trial (ISAT) study, published in $2002^{1}$, and their subsequent results ${ }^{2,3}$. Some years ago, in 1999, the public health system of Brazil included this treatment as routine for selected centers, permitting the real development of the technique in this country, and even some publications about results were obtained ${ }^{4}$.

We have a system in which a restricted number of coils are available to treat each lesion. Initially, this number was restricted to 6 coils per aneurysm (2000), changing to a scale based on the size of the aneurysm in 2006 from 6-12 coils per aneurysm and again reduced to 7-10 coils in December of 2010 by the government.

This system causes a problem in a lot of cases in that more coils are needed to occlude the aneurysm sac satisfactorily (defined as results Class 1 or 2 following the Raymond's classification $)^{5}$, leading to clinical and angiographic results, which are not effective.

\footnotetext{
${ }^{1} \mathrm{MD}$; Interventional Neuroradiology of the Neurology and Neurosurgery Service, Passo Fundo RS, Brazil;

${ }^{2} \mathrm{MD}$, PhD; Interventional Neuroradiology/Vascular and Interventional Radiology, Hospital das Clínicas, School of Medicine of Ribeirão Preto, University of São Paulo (USP), Ribeirão Preto SP, Brazil;

${ }^{3} \mathrm{MD}$; Interventional Neuroradiology, Hospital das Clínicas, Federal University of Minas Gerais (UFMG), Belo Horizonte MG, Brazil;

${ }^{4} \mathrm{MD}$; Interventional Neuroradiology, Service de Neuroradiologie Interventionnelle, Hôpital Beaujon, Paris, France.

Correspondence: José Ricardo Vanzin; Rua Teixeira Soares 640; 99010-080 Passo Fundo RS - Brasil; E-mail:vanzin@neurosnn.com.br

Conflict of interest: There is no conflict of interest to declare.

Received 18 July 2011; Received in final form 23 January 2012; Accepted 30 January 2012
} 
The aim of this study was to establish the quantity of coils needed to occlude each aneurysm based on its size, following the International Study of Unruptured Intracranial Aneurysms Investigators (ISUIA) classification ${ }^{6}$. This retrospective study was performed analyzing a database of almost 1000 aneurysms treated between 1999 and 2003 at the Rothschild Foundation (Paris - France).

\section{METHODS}

\section{Patient population}

We used the database from one of the most important and the large volume interventional neuroradiology services worldwide: the Rothschild Foundation in Paris - France.

All the patients with intracranial aneurysms treated by endovascular approach with detachable coils from January 1999 to December 2003 were retrospectively included. The data collection was got by extensive medical records review. There were ruptured and unruptured lesions.

\section{Aneurismal characteristics}

Aneurismal characteristics comprised anatomical features - long axis, neck size and location. All aneurysms were analyzed based on the 3D reconstruction (Biplane Philips Allura 3D-RA - Netherlands). The largest aneurismal diameter was measured in millimeters and classified as: small $(<7 \mathrm{~mm})$, medium $(7-12 \mathrm{~mm})$, large $(>12$ to $25 \mathrm{~mm}$ ) and giant ( $>25 \mathrm{~mm}$ ), following the groups proposed by the ISUIA study ${ }^{5}$. The measure for aneurismal neck was obtained based on the optimal projections to visualize the neck of the aneurysm and classify it in small $(<4 \mathrm{~mm})$ and large ( $\geq 4 \mathrm{~mm})$.

The measurement of the aneurysm was obtained considering the largest diameter on the 3D image reconstruction. The 3D reconstruction is very reliable to evaluate the diameter of the vessel or aneurysm, and the technical aspects of the measure methodology were detailed and established by other publications ${ }^{7-10}$. To assure the reliability of the measurement, the equipments that possess the 3D reconstruction technology go through rigorous calibrations periodically.

\section{Endovascular treatment}

All aneurysms treated with detachable coils were reviewed. Liquid embolic agents, as Onyx", were excluded. Four brands of coils were used: Guglielmi detachable coils (GDC; Boston Scientifics/Target, Fremont, CA), Sapphire (Micro Therapeutics Inc., Irvine, CA) and its earlier models (Dendron $\mathrm{GmbH}$, a subsidiary of Micro-Therapeutics, Inc, Bochum, NRW, Germany), Microplex (Microvention, Aliso Viejo, CA) and Trufill DCS detachable coil (Cordis, Miami Lakes, FL). The combination of more than one brand during the endovascular treatment was frequently applied, usually based on the experience of the endovascular surgeon concerning options related with shape and softness.

\section{Statistical analysis}

The data were analyzed in SDA (version 6.0.93). For the independent group, it was used the single sample $t$-test, Fishers' exact probability for dichotomies and $\chi^{2}$ test for parameter-free.

\section{RESULTS}

\section{Patients and aneurysms}

A total of 892 patients with 983 intracranial aneurysms were enrolled. Out of these intracranial aneurysms, 869 aneurysms (88.4\%) were treated selectively using platinum coils, 83 cases $(8.6 \%)$ were dissecting large or giant aneurysms treated by parent-vessel occlusion and 29 aneurysms $(2.9 \%)$ were sent to surgical clipping and excluded from this study. Out of 952 patients that were studied, the main age was 49.5 years old and $66.1 \%$ of the patients were women. The majority of patients had ruptured aneurysms (63.7\%) and was treated during the acute phase (93.1\%). The mean aneurismal neck was $4 \mathrm{~mm}$ (1 to $16.6 \mathrm{~mm}$ ). The location was divided in anterior circulation (813 aneurysms - 85.4\%) and posterior circulation (139 aneurysms - 14.6\%). Out of the anterior circulation 356 aneurysms were of internal carotid artery, 196 aneurysms of middle cerebral artery and 261 of anterior cerebral artery.

\section{Aneurysm size and numbers of coils}

In the total, 7,543 coils were used, varying from 1 to 41 coils per aneurysm, with a mean of 7.9. The mean diameter of the sac was $8.2 \mathrm{~mm}$ (1.9 to $70 \mathrm{~mm}$ ). There was a direct relationship between the size of the aneurysm and the amount of coils used with $\mathrm{p}<0.001$. Out of 952 intracranial aneurysms, 462 aneurysms were small $(<7 \mathrm{~mm}), 315$ aneurysms were medium ( 7 to $12 \mathrm{~mm}$ ), 135 aneurysms were large (>12 to $25 \mathrm{~mm}$ ) and 40 aneurysms were giants (>25 mm). Out of 462 small aneurysms, a mean standard deviation (mean SD) of size was $4.8 \pm 1.2 \mathrm{~mm}$ (1.9 to $6.9 \mathrm{~mm}$ ) and a total of 1,666 coils were deployed with mean SD $4.6 \pm 2.3$ coils/aneurysm (1 to 11 coils). Out of medium aneurysms, a mean SD of size was $8.6 \pm 1.6 \mathrm{~mm}$ (7 to $12 \mathrm{~mm}$ ) and a total 2,567 coils, mean SD 8.2 \pm 3.8 coils/aneurysm ( 3 to 25 coils). Out of large aneurysm, a mean of size was $17 \pm 3.3 \mathrm{~mm}$ (12.1 to $25 \mathrm{~mm}$ ) and a total 2,114 coils, mean SD 16.1 \pm 3.8 coils/aneurysm (7 to 32 coils). Out of giant aneurysms, a mean SD of size were $32 \mathrm{~mm} \pm 8.8 \mathrm{~mm}$ ( 25 to $70 \mathrm{~mm}$ ) and a total 1,087 coils, mean SD $28.7 \pm 7.2$ coils/aneurysm ( 12 to 41 coils). The balloon-assisted coil embolization (remodeling technique) was performed in 294 cases (33.9\%). Most aneurysms were treated only once (98.9\%), $0.9 \%$ was treated twice and $0.2 \%$ three times in order to obtain a satisfactory angiographic result. A stent was deployed in 23 cases (2.6\%). The neck aneurysm size did not influence the number of coils needed to occlude an aneurysm. 


\section{DISCUSSION}

The analysis of aneurysm size and number of coils revealed that as larger the aneurysm, more coils are needed to obtain satisfactory occlusion. Statistical analyses showed statistical substantial differences regarding the numbers of coils according to the size of the aneurysm treated; $p<0.001$. Thus this study shows that as the aneurysm size grows more coils are needed. The mean number of coils deployed was almost eight coils per aneurysm, and the mean diameter of all aneurismal sacs was $8 \mathrm{~mm}$.

The data collection was retrospective, which hindered a more complex analysis of the aneurismal measurement, such as three axis or volume. Nevertheless, the longest axis evaluation is a simple and applicable technique that can be used in the daily practice. Additionally, the longest axis is the parameter considered nowadays for the Brazilian government as reference to the number of coils allowed to treat an aneurysm by endovascular approach.

The relation of one coil for each millimeter of the sac seems to be stable when we divide the aneurysms by group of sizes (Table 1). Small aneurysms had mean size of $4.8 \pm 1.2 \mathrm{~mm}$ and mean of $4.6 \pm 2.3$ coils used. Medium aneurysms had mean size of $8.6 \pm 1.6 \mathrm{~mm}$ and $8.2 \pm 3.8$ coils. Out of large aneurysm, a mean size of $17 \pm 3.3 \mathrm{~mm}$ and $16.1 \pm 3.8$ coils was found. For giant aneurysm, a mean of size of $32 \pm 8.8 \mathrm{~mm}$ and $28.7 \pm 7.2$ coils. Maybe a solution for National Health System or Private System to predict the numbers of coils we need to treat our patients is one coil for each millimeter of the aneurysmal sac.

It is important to consider that a great variation of number of coils was observed. For example, out of small aneurysms ( $<7 \mathrm{~mm}$ ), a mean SD were $4.6 \pm 2.3$ coils/aneurysm, showing a variation of 1 to 11 coils used. It is impossible to predict exactly how much coils we will need to use, but an approximation can be done. In fact, the number of coils to occlude an aneurysm depends on many factors: experience of the interventional neuroradiologist; kind of coils; length; thickness and softness, and the shape of the aneurysm (round, elongated, lobulated). Currently we have more than 6 types of coils available for aneurysm embolization (Stryker, Codman, ev3, Micrus, Microvention, etc) and more than 100 types of coils by each industry regarding the size, length, thickness, combination of platinum with expanding hydrogel polymer and polyglycolic-polylactic acid (PGLA).

Recently, we had two health public system communicates in Brazil (Ordinance ${ }^{\circ}$ 694, December of 2010 and Ordinance $\mathrm{n}^{\circ} 189$, April of 2011) that reduced the number of coils for the endovascular treatment. The Brazilian government proposed to use 7 coils for the intracranial aneurysms $<15 \mathrm{~mm}$ and 10 coils for $>15 \mathrm{~mm}$. Using the Rothschild Foundation data, we observed a necessity of 10.6 coils per aneurysm $<15 \mathrm{~mm}$ and 21.3 coils per aneurysm $>15 \mathrm{~mm}$ (Table 2 ). When we compare to the last communicate, it becomes clear that there is a real problem regarding the amount of coils available for endovascular treatment of each intracranial aneurysms. Analyzing the older system, we can see that it is impossible to use 6 coils for aneurysms $<8 \mathrm{~mm}, 8$ coils for aneurysms 8 to 15 $\mathrm{mm}$ and 12 coils for the aneurysms $>15 \mathrm{~mm}$. Using data from this article, we found that it is necessary to use 8.7 coils per aneurysm smaller than $8 \mathrm{~mm}, 11.7$ coils per aneurysm from 8 to $15 \mathrm{~mm}$ and 21.3 coils per aneurysm of $>15 \mathrm{~mm}$ (Table 3 ).

Moreover, nowadays, several additional devices are available for the treatment of intracranial aneurysms with clear benefits in terms of stability over the time, such as the selfexpandable intracranial stents ${ }^{11-14}$ and Onyx ${ }^{15-18}$. More recently, there is a new stent capable to change the direction of the flow ( flow diverter stent) inside aneurism sac occluding it ${ }^{19,20}$. Of course, these devices should be considered for the treatment of selected cases ${ }^{21,22}$.

The superiority of this method compared to open surgery has been strongly shown at level 1 of evidence by ISAT study ${ }^{1}$ and reinforced by its subsequent publications ${ }^{2,3}$. In the casuistics analysed, more than $95 \%$ of the aneurysms were embolized. Even in the public health system in Brazil, almost 47\% of the intracranial aneurysms are embolized nowadays ${ }^{23}$ and these numbers are growing. The endovascular treatment of intracranial aneurysms is now a reality and must not be denied.

This article reviews a very large series of aneurysms treated by endovascular approach at a single center. The actual system proposed by the National Health System in Brazil does not allow adequate treatment of most intracranial aneurysms by endovascular approach. The consequence is that many patients are not receiving the best treatment available.

The relation of one coil for each millimeter of the aneurysm sac was proven by extensive statistical analysis. Maybe this number should be considered as guidance to the National Health System and Private System to determine a predictive value of the number of coils required to obtaining an acceptable endovascular treatment of each intracranial aneurysm.

Table 1. Size of aneurysms and number of coils.

\begin{tabular}{lcccc} 
& $<7 \mathrm{~mm}$ & $7-15 \mathrm{~mm}$ & $16-25 \mathrm{~mm}$ & $>25 \mathrm{~mm}$ \\
Size & $4.8 \pm 1.2$ & $8.6 \pm 1.6$ & $17 \pm 3.3$ & $32 \pm 8.8$ \\
Number of coils & $4.6 \pm 2.3$ & $8.2 \pm 3.8$ & $16.1 \pm 3.8$ & $28.7 \pm 7.2$ \\
\hline
\end{tabular}

Table 2. Correlation between Moret's data and Brazilian Ordinance - April of 2011.

\begin{tabular}{lcc} 
& $<15 \mathrm{~mm}$ & $>15 \mathrm{~mm}$ \\
Moret's data & 10.6 & 21.3 \\
Ordinance 189 & 7 & 10 \\
\hline
\end{tabular}

Table 3. Correlation between Moret's data and Brazilian Ordinance - December 2010.

\begin{tabular}{lccc} 
& $\langle 8 \mathrm{~mm}$ & $8-15 \mathrm{~mm}$ & $>15 \mathrm{~mm}$ \\
Moret's data & 8.7 & 11.7 & 21.3 \\
Ordinance 694 & 6 & 8 & 12 \\
\hline
\end{tabular}




\section{References}

1. MolyneuxA, Kerr R, Stratton I, etal. and the International Subarachnoid Aneurysm Trial (ISAT) Collaborative Group. International Subarachnoid Aneurysm Trial (ISAT) of neurosurgical clipping versus endovascular coiling in 2143 patients with ruptured intracranial aneurysms: a randomised trial. Lancet 2002;360:1267-1274

2. Molyneux AJ, Kerr RS, Yu LM, et al. and the International Subarachnoid Aneurysm Trial (ISAT) Collaborative Group. International subarachnoid aneurysm trial (ISAT) of neurosurgical clipping versus endovascular coiling in 2143 patients with ruptured intracranial aneurysms: a randomised comparison of effects on survival, dependency, seizures, rebleeding, subgroups, and aneurysm occlusion. Lancet 2005;366:809-817.

3. Molyneux AJ, Kerr RSC, Birks J, et al. Risk of recurrent subarachnoid haemorrhage, death, or dependence and standardized mortality ratios after clipping or coiling of an intracranial aneurysm in the International Subarachnoid Aneurysm Trial (ISAT): long-term followup. Lancet Neurol 2009;8:427-433.

4. Abud DG, Nakiri GS, Abud TG, Carlotti Jr CG, Colli BO, Santos AC. Endovascular therapy for selected (most non-surgical) intracranial aneurysms in a Brazilian University Hospital. Arq Neuropsiquiatr 2010;68:764-769.

5. Roy D, Milot G, Raymond J. Endovascular treatment of unruptured aneurysms. Stroke 2001;32:1998-2004.

6. Wiebers DO, Whisnant JP, Huston J, et al. Unruptured intracranial aneurysms: natural history, clinical outcome, and risks of surgical and endovascular treatment. Lancet 2003;362:103-110.

7. Ishihara S, Ross IB, Piotin M, Weill A, Aerts H, Moret J. 3D Rotational angiography: recent experience in the evaluation of cerebral aneurysms for treatment. Interv Neuroradiol 2000;30:85-94.

8. Piotin M, Gailloud P, Bidaut L, et al. CT angiography, MR angiography and rotational digital subtraction angiography for volumetric assessment of intracranial aneurysms. An experimental study. Neuroradiology 2003;45:404-409.

9. Piotin M, Spelle L, Mounayer C, et al. Intracranial aneurysms: treatment with bare platinum coils-aneurysm packing, complex coils, and angiographic recurrence. Radiology 2007;243:500-508.

10. Beck J, Rohde S, Berkefeld J, Seifert V, Raabe A. Size and location of ruptured and unruptured intracranial aneurysms measured by 3-dimensional rotational angiography. Surg Neurol 2006;65:18-25.

11. Alfke K, Straube T, Dörner L, Mehdorn HM, Jansen O. Treatment of intracranial broad-neck aneurysms with a new self-expanding stent and coil embolization. AJNR Am J Neuroradiol 2004:25:584-591.
12. Brisman JL, Song JK, Niimi Y, Berenstein A. Treatment options for widenecked intracranial aneurysms using a self-expandable hydrophilic coil and a self-expandable stent combination. AJNR Am J Neuroradiol 2005;26:1237-1240.

13. Piotin M, Blanc R, Spelle L, et al. Stent-assisted coiling of intracranial aneurysms: clinical and angiographic results in 216 consecutive aneurysms. Stroke 2010;41:110-115.

14. Mocco J, Snyder KV, Albuquerque FC, et al. Treatment of intracranial aneurysms with the Enterprise stent: a multicenter registry. J Neurosurg 2009;110:35-39.

15. Molyneux AJ, Cekirge S, Saatci I, Gál G. Cerebral Aneurysm Multicenter European Onyx (CAMEO) trial: results of a prospective observational study in 20 European centers. AJNR Am J Neuroradio 2004;25:39-51.

16. Piske RL, Kanashiro LH, Paschoal E, Agner C, Lima SS, Aguiar $\mathrm{PH}$. Evaluation of Onyx HD-500 embolic system in the treatment of 84 wide-neck intracranial aneurysms. Neurosurgery 2009; 64:865-875.

17. Simon SD, Eskioglu E, Reig A, Mericle RA. Endovascular treatment of side wall aneurysms using a liquid embolic agent: a US single-center prospective trial. Neurosurgery 2010;67:855-860.

18. Tevah J, Senf R, Cruz J, Fava M. Endovascular treatment of complex cerebral aneurysms with onyx hd-500(®) in 38 patients. J Neuroradiol 2011;38:283-290

19. Byrne JV, Beltechi R, Yarnold JA, Birks J, Kamran M. Early experience in the treatment of intra-cranial aneurysms by endovascular flow diversion: a multicentre prospective study. PLoS One 2010;5.

20. Lubicz B, Collignon L, Raphaeli G, et al. Flow-diverter stent for the endovascular treatment of intracranial aneurysms: a prospective study in 29 patients with 34 aneurysms. Stroke 2010;41: 2247-2253.

21. Pierot L. Flow diverter stents in the treatment of intracranial aneurysms: Where are we? J Neuroradiol 2011;38:40-46.

22. Raphaeli G, Collignon L, Bruneau M, Witte OD, Lubicz B. Endovascular treatment of posterior circulation fusiform aneurysms: single-centre experience in 31 patients. Neurosurgery 2011;69:274-283.

23. DATASUS. Internações por especialidade e local de internação 1981 a 2007 e a partir de 2008. Available at : http://www2.datasus. gov.br/DATASUS/index.php?area =0202\&VObj=http://tabnet. datasus.gov.br/cgi/deftohtm.exe?sih/cnv/sx [cited 2011 Sept 05]. 